\title{
Efeitos do Tamoxifeno e dos Estrogênios Conjugados no Epitélio Mamário de Ratas em Estro Permanente
}

\author{
Effects of Tamoxifen and Conjugated Estrogens on the Mammary Epithelium of \\ Rats in Persistent Estrus
}

\begin{abstract}
Benedito Borges da Silva, Luiz Henrique Gebrim, Manuel de Jesus Simões, Edmund Chada Baracat, Geraldo Rodrigues de Lima
\end{abstract}

\begin{abstract}
RESUM0
Objetivo: avaliar as alterações morfológicas e morfométricas produzidas pelo tamoxifeno e pelos estrogênios conjugados no epitélio mamário de ratas em estro permanente.

Métodos: foram utilizadas 33 ratas adultas, induzidas a estro permanente com 1,25 mg de propionato de testosterona e divididas ao acaso em três grupos: GI - que receberam apenas água, servindo como controle ( $n=12) ; G I I$ - tratadas com $500 \mu \mathrm{g}$ de tamoxifeno diariamente $(n=10)$; GIII - tratadas com $30 \mu \mathrm{g}$ de estrogênios conjugados ao dia $(n=11)$. O primeiro par mamário abdômino-inguinal dos animais foi extirpado e processado para estudo morfológico e morfométrico. Os dados foram analisados estatisticamente pela análise de variância por postos de Kruskal-Wallis ( $p<0,05)$.

Resultados: o estudo morfológico revelou sinais de atrofia epitelial e o estudo morfométrico exibiu redução estatisticamente significante do número médio de ductos e alvéolos nos grupos II (10,1 e 1,9, respectivamente) e III (1 1, 1 e 3,5, respectivamente) em relação ao grupo I (25,0 e 6,6, respectivamente). Não houve diferença estatística entre os grupos II e III.

Conclusões: os resultados deste estudo indicam que tanto o tamoxifeno como os estrogênios conjugados, nas doses e no tempo utilizado, produziram atrofia no epitélio mamário de ratas em estro permanente.
\end{abstract}

PALAVRAS-CHAVE: Mama normal. Terapia de reposição hormonal. Antiestrogênios.

\section{Introdução}

Há muitas controvérsias a respeito dos efeitos dos estrogênios conjugados e do tamoxifeno na mama normal. A comprovação de uma ação antiestrogênica poderia ser útil para a redução da atividade proliferativa da mama de pacientes em uso de terapêutica de reposição hormonal.

Os estrogênios conjugados representam uma combinação complexa de sulfato esteróides, extraídos da urina de éguas prenhes ${ }^{1}$. Apesar de seu largo uso clínico, por mais de 50 anos, a literatura carece de estudos sobre seus efeitos tanto

Disciplina de Ginecologia da Universidade Federal de São Paulo - Escola Paulista de Medicina Correspondência:

Benedito Borges da Silva

Rua Wilson Soares, 95 - Bairro São Cristóvão

64052-310 - Teresina - PI

Telefone: (86) 2325063

Fax: (86) 2232170 na mama humana normal quanto na mama de animais de laboratório. Alguns estudos epidemiológicos não evidenciaram aumento no risco de câncer de mama quando foram usados estrogênios conjugados na dose de $0,625 \mathrm{mg}$ ao dia e por longos períodos ${ }^{2}$, ao passo que outros têm mostrado, até mesmo, uma redução. Isto nos levaria a questionar se os estrogênios conjugados agiriam de maneira diferente daquela do estradiol ou se teriam alguma ação similar à do tamoxifeno.

O tamoxifeno pode ter um efeito estrogênico parcial ou total ou antiestrogênico a depender do tecido alvo e da espécie em estudo ${ }^{3,4}$. A droga mostrou-se eficiente em inibir o desenvolvimento de tumores mamários de ratas, normalmente induzidos por carcinogênios como o dimetilbenzantraceno ${ }^{5}$. Também inibiu completamente os efeitos do benzoato de estradiol no crescimento dos ductos mamários de ratas adultas castradas ${ }^{6}$. Assim, poderíamos supor que um epitélio mamário sob 
estimulação estrogênica contínua, como o de ratas em estro permanente, seria útil para o estudo dos efeitos antiestrogênicos do tamoxifeno e de algum efeito similar dos estrogênios conjugados.

Contudo, pouco se conhece sobre os efeitos do tamoxifeno e dos estrogênios, conjugados em um epitélio mamário normal sob constante estimulação estrogênica. $O$ presente trabalho tem por objetivo comparar os aspectos morfológicos e morfométricos do epitélio mamário de ratas em estro permanente, tratadas com tamoxifeno e com estrogênios conjugados.

\section{Material e Métodos}

Foram utilizadas 33 ratas adultas virgens (Rattus novergicus albinus) em estro permanente obtido pela injeção subcutânea de 1,25 mg de propionato de testosterona no segundo dia de vida ${ }^{7}$. O estro permanente foi confirmado por colpocitologia hormonal, realizada por duas semanas, a partir dos 70 dias de vida. Os animais foram então divididos ao acaso em três grupos: grupo I, controle ( $\mathrm{n}=12)$, que receberam apenas $1 \mathrm{ml}$ de água destilada diariamente por 30 dias; grupo II $(n=10)$, que receberam $500 \mu \mathrm{g}$ de tamoxifeno diários diluídos em água destilada e administrados por gavagem durante 30 dias, e grupo III $(n=11)$ que receberam $30 \mu \mathrm{g}$ de estrogênios conjugados, administrados da mesma maneira e por igual periodo de tempo.

No $31^{\circ}$ dia, os animais foram sacrificados para remoção do primeiro par mamário abdôminoinguinal, que foi fixado em Bouin por $72 \mathrm{~h}$, sendo então processado e corado pelo método de H-E para estudo em microscopia óptico. Para análise morfométrica referente à contagem de ductos e alvéolos foram utilizados princípios de estereologia de acordo com Weibel e Gomez ${ }^{8}$, que preconizam a contagem somente dos pontos do retículo que interceptam a estrutura estudada. Para tal, utilizouse ocular KPL 10X, da Zeiss, com retículo de integração (Integrationplate I) contendo 25 pontos, acoplados a microscópio óptico com aumento de 100 vezes. Para cada lâmina, foram estudados 10 campos aleatórios pelo sistema de varredura horizontal, num total de 250 pontos. Os dados foram analisados estatisticamente pelo teste da análise da variância por postos de Kruskal-Wallis $(p<0,05)$.

\section{Resultados}

O estudo morfológico do grupo controle revelou lóbulos exibindo grande concentração de alvéolos revestidos por células cúbicas, dilatados e contendo secreção eosinofilica. Os ductos, por sua vez, encon- travam-se em maior concentração que os alvéolos e, à semelhança destes, dilatados e contendo material eosinofilico (Figura 1). Os grupos II (tamoxifeno) e III (estrogênios conjugados) exibiram menor concentração de ductos e alvéolos, pouco desenvolvidos e com secreção escassa ou ausente (Figuras 2 e 3).

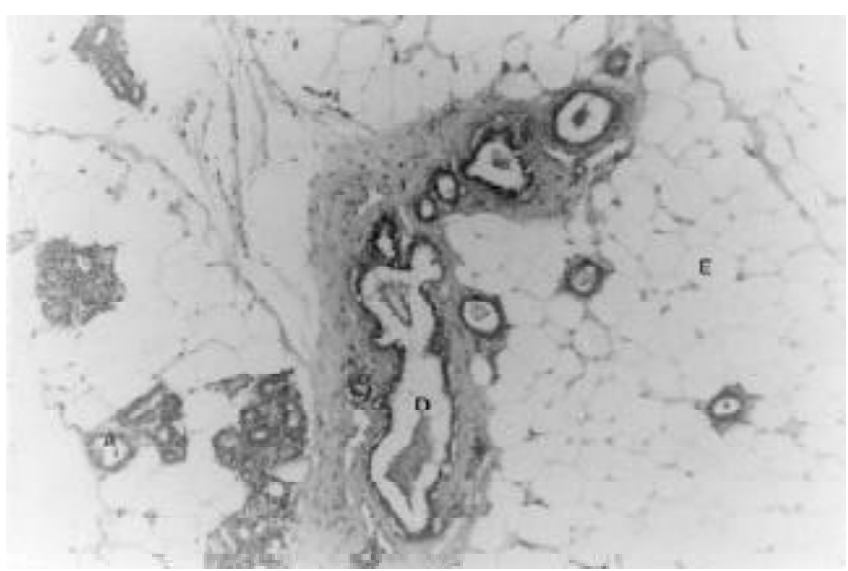

Figura 1 - Fotomicrografia de corte histológico de mama de rata em estro permanente (controle). Notar a presença de ducto (D) e alvéolos (A) dilatados, contendo secreção. Estroma (E) abundante. Coloração H-E (140X).

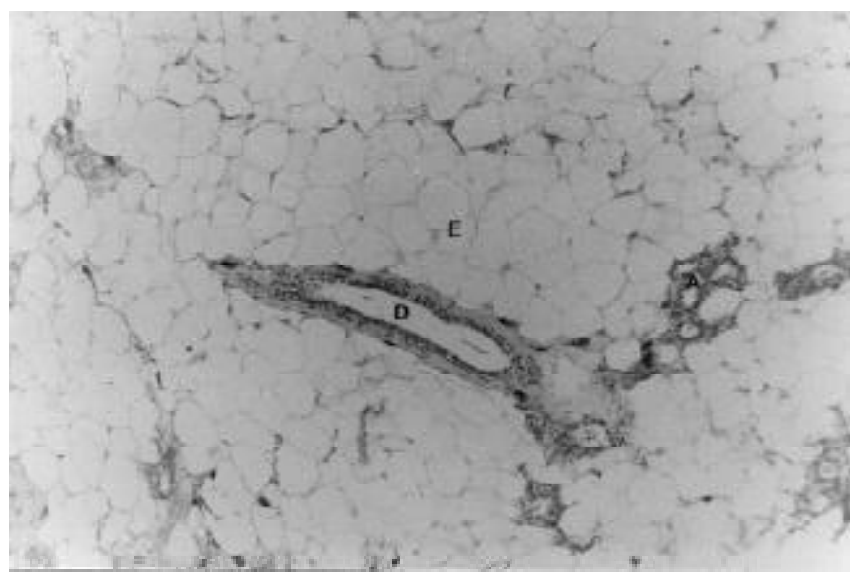

Figura 2 - Fotomicrografia de corte histológico de mama de rata em estro permanente tratada com tamoxifeno. Observar a presença de ducto (D) e alvéolos (A) pouco desenvolvidos com secreção escassa. Estroma (E) abundante. Coloração H-E (140X).

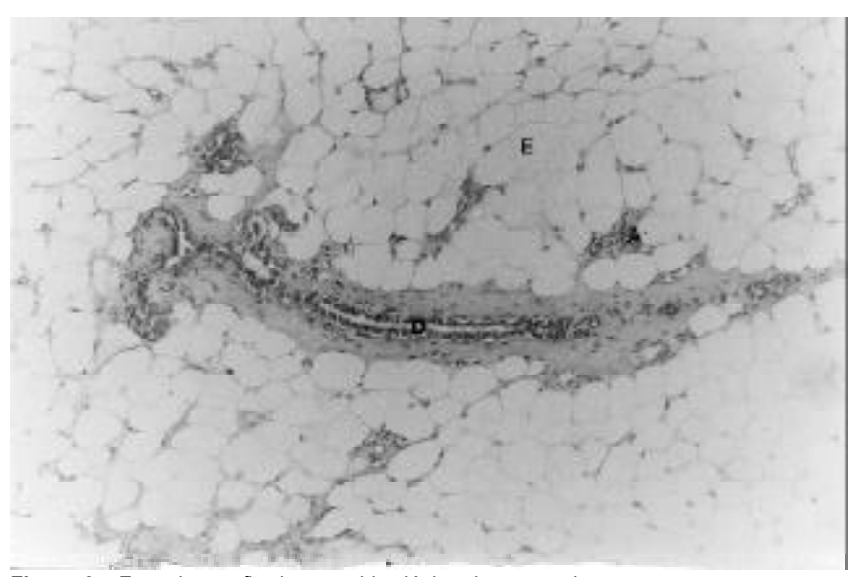

Figura 3 - Fotomicrografia de corte histológico de mama de rata em estro permanente tratada com estrogênios conjugados. Observar a presença de ductos (D) e alvéolos (A) pouco desenvolvidos e sem secreção. Estroma (E) abundante. Coloração H-E (140X). 
A análise dos dados morfométricos mostra uma redução significante do número médio de ductos dos grupos II e III, 10,1 e 11,2, respectivamente, em relação ao grupo controle, 25,0 (Tabela 1). Da mesma maneira, constatou-se uma redução significante do número médio de alvéolos dos grupos II e III, 1,9 e 3,5, respectivamente, em relação ao grupo controle, 6,6 (Tabela 2).

Tabela 1 - Número médio de ductos mamários nos grupos I (controle), II (tamoxifeno) e III (estrogênios conjugados) em 10 campos, com aumento de 100 vezes.

\begin{tabular}{|c|c|c|c|}
\hline & \multicolumn{3}{|c|}{ Grupos } \\
\hline & I & II & III \\
\hline & 23 & 12 & 13 \\
\hline & 24 & 12 & 11 \\
\hline & 25 & 8 & 12 \\
\hline & 33 & 11 & 12 \\
\hline & 37 & 8 & 8 \\
\hline & 25 & 12 & 8 \\
\hline & 27 & 9 & 12 \\
\hline & 22 & 11 & 11 \\
\hline & 22 & 7 & 12 \\
\hline & 23 & 11 & 11 \\
\hline & 17 & & 12 \\
\hline & 22 & & \\
\hline Média & 25,0 & 10,1 & 11,1 \\
\hline
\end{tabular}

Tabela 2 - Número médio de ductos mamários nos grupos I (controle), II (tamoxifeno) e III (estrogênios conjugados) em 10 campos, com aumento de 100 vezes.

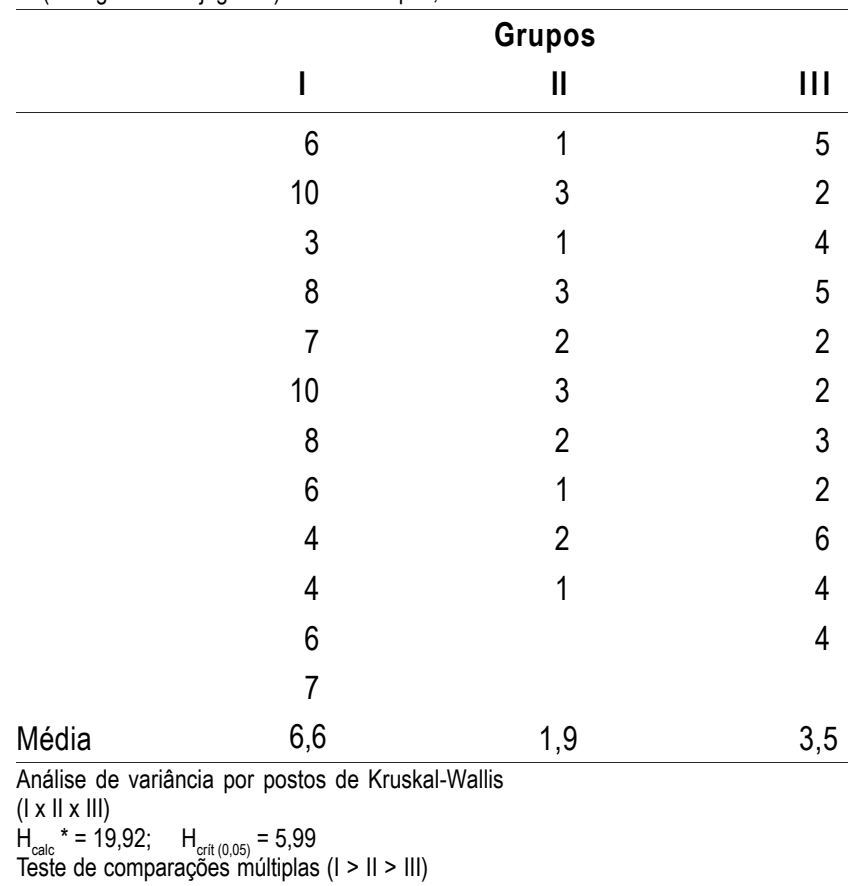

\section{Discussão}

A terapêutica de reposição hormonal encontra-se cercada de muitas controvérsias pela possibilidade de aumentar o risco para câncer de mama, principalmente em pacientes de alto risco. Há também a possibilidade de se fazer quimioprevenção do câncer de mama com tamoxifeno em pacientes de alto risco, porém não se chegou a um consenso sobre a relação entre o uso de tamoxifeno e estrogênios conjugados e o risco de câncer de mama ${ }^{9}$. Além do mais, por razões de natureza ética, torna-se dificil estudar os efeitos destas drogas no epitélio mamário humano normal.

$\mathrm{Na}$ presente investigação utilizamos ratas em estro permanente com o intuito de estudar os efeitos do tamoxifeno e dos estrogênios conjugados na mama destes animais. As drogas foram diluídas com água destilada e administradas por via oral à semelhança da via comumente utilizada pelas mulheres. As doses empregadas podem parecer altas para alguns autores ou mesmo baixas para outros, pois há dificuldades de se estabelecer equivalência de doses entre as diversas espécies em face das diferenças principalmente na absorção e no metabolismo das drogas.

De Gregorio et al. ${ }^{10}$, após estudos em ratos sobre vias de administração e equivalência de doses, postularam que $1.000 \mu \mathrm{g}$ ao dia de tamoxifeno, por via subcutânea, resultariam em níveis similares aos das mulheres usando $20 \mathrm{mg}$ da droga ao dia. Portanto, o dobro da dose empregada nesse estudo $(500 \mu \mathrm{g})$ e por via oral. No que se refere aos estrogênios conjugados, Orimo et al. ${ }^{11}$ empregaram $25 \mu \mathrm{g}$ e $100 \mu \mathrm{g}$ ao dia, por via oral, com objetivo de prevenir osteoporose induzida em ratos, obtendo o efeito desejado com a dose de 100 $\mu \mathrm{g}$. Com dose inferior a esta, $30 \mu \mathrm{g}$ diários, embora cerca de cinco a 10 vezes a dose equivalente comumente usada na reposição hormonal, observamos efeitos na mama de ratas em estro permanente.

A glândula mamária das ratas em estro permanente (controle) exibiu grande concentração de ductos e alvéolos, que se encontravam dilatados e contendo secreção. Estes achados poderiam sobrevir do contínuo influxo de estrogênios e da maior liberação de prolactina e estão de acordo com aqueles relatados por Jacobsohn e Norgren ${ }^{12}$.

A atrofia mamária produzida pelo tamoxifeno poderia advir de sua ação antiestrogênica por meio da inibição na molécula do receptor de estrogênio da função de ativação da transcrição gênica 2, predominante na mama ${ }^{13}$. Uma outra hipótese seria a supressão pelo tamoxifeno de algum gene tal 
como o gene CD36, envolvido na angiogênese, demonstrada tanto em tecido mamário humano normal quanto em neoplásico ${ }^{14}$. Já a ação regressiva produzida pelos estrogênios conjugados é intrigante, pois trata-se de um epitélio proliferado que recebeu mais estímulo estrogênico. Uma das hipóteses que poderia ser aventada para explicação do fenômeno seria a sua complexa constituição, pois é formado por mais de 10 sulfato esteróides e pelo menos um deles (equilenina ou 17hidroxiequilenina) pode bloquear os efeitos do estradiol no epitélio mamário de maneira similar ao tamoxifeno ${ }^{15}$.

Assim, o presente estudo mostra que tanto o tamoxifeno como os estrogênios conjugados nas doses testadas produziram atrofia no epitélio mamário de ratas em estro permanente. Contudo, não sabemos se tais resultados podem ser extrapolados para a espécie humana, o que requer mais estudos.

\section{SUMMARY}

Purpose: to evaluate the morphologic and morphometric alterations produced by tamoxifen and conjugated estrogens in the mammary epithelium of rats in persistent estrus. Methods: thirty-three adult female rats in persistent estrus induced with $1.25 \mathrm{mg}$ testosterone propionate were divided at random into three groups: GI-which received only water, control group $(n=12)$; GII-treated with $500 \mu \mathrm{g}$ tamoxifen daily $(n=10) ; G I I I$ - treated with $30 \mu g$ conjugated estrogens per day $(n=11)$. The first inguinal-abdominal pair of mammary glands of the animals was extirpated and processed for morphologic and morphometric study. Data were analyzed statistically by the Kruskal-Wallis rank analysis of variance $(p<0.05)$.

Results: the morphologic study revealed signs of epithelial atrophy and the morphometric study showed a statistically significant reduction in the mean number of ducts and alveoli in groups II (10.1 and 1.9, respectively) and III (11.1 and 3.5, respectively) compared to group I (25.0 and 6.6, respectively). There was no significant difference between groups II and III.

Conclusions: the results of this study indicate that tamoxifen as well as conjugated estrogens at the tested doses produced mammary epithelial atrophy in rats in persistent estrus.

KEY WORDS: Normal breast. Hormonal replacement therapy. Antiestrogens.

\section{Referências}

1. Troy SM, Hicks DR, Parker VD, Jusko WJ, Rofsky HE, Poster RJ. Differences in pharmacokinetics and comparative bioavailability between Premarin ${ }^{\circledR}$ and Estab ${ }^{\circledR}$ in healthy postmenopausal women. Curr Ther Res 1994; 55: 359-73.

2. Dupont WD, Page DL. Menopausal estrogen replacement therapy and breast cancer. Arch Intern Med 1991; 151: 67-72

3. Buckey MM, Goa KL. Tamoxifen, a reappraisal of its pharmacodynamic and pharmacokinetic properties and therapeutic use. Drugs 1989; 37:451-90.

4. Jordan VC. An overview of considerations for testing of tamoxifen as a preventive for breast cancer. Ann N Y Acad Sci 1995; 768: 141-7

5. Jordan VC. Effect of tamoxifen (ICI 46474) on initiation and growth of DMBA-induced rat mammary carcinomata. Eur J Cancer 1976; $12: 419-24$.

6. Götze RA, Nishino Y, Neumann F. Anti-oestrogenic effects of tamoxifen on mammary gland and hypophysis in female rats. Acta Endocrinol (Copenh) 1984; 105: 360-70

7. Barraclough CA. Production of anovulatory sterile rats by single injections of testosterone propionate. Endocrinology 1961; 68: 62-7.

8. Weibel ER, Gomez DM. A principle of counting tissue structures on random sections. J Appl Physiol 1962; 17: 343-8

9. Powles TJ, Jones AL, Ashley SE, O’Brien ME, Tidy VA, Treleavan J, et al. The Royal Marsden Hospital pilot tamoxifen chemoprevention trial. Breast Cancer Res Treat 1994; 31: 73-82.

10.De Gregorio MW, Wilbur BJ, Coronado E, Osborne CK. Serum tamoxifen concentrations in the athymic nude mouse after three methods of administration. Cancer Chemother Pharmacol 1987; 20: 316-8.

11.Orimo H, Fujita T, Yoshikawa M, Hayano K, Sakurada T. Effect of estrogen on immobilization osteoporosis in rat. Endocrinology 1971; 88: 102-5.

12.Jacobsohn D, Norgren A. Early effects of testosterone propionate injected into 5 day old rats. Acta Endocrinol (Copenh) 1965; 49: 453-65.

13. Howell A. New endocrine treatment for breast cancer: biological and clinical aspects. Breast 1996; 5:170-4.

14.Silva ID, Salicioni AM, Russo IH, Higgy NA, Gebrim LH, Russo J. Tamoxifen down-regulates CD36 messenger RNA levels in normal and in neoplastic human breast tissues. Cancer Res 1997; 57: 378-81.

15.Schwartz J, Freeman R, Frishman W. Clinical pharmacology of estrogens: cardiovascular actions and cardioprotective benefits of replacement therapy in postmenopausal women. $\mathrm{J}$ Clin Pharmacol 1995; 35: 1-16. 